Article

\title{
The Influence of Maltodextrin and Inulin on the Physico-Chemical Properties of Cranberry Juice Powders
}

\author{
Anna Michalska-Ciechanowska ${ }^{1,2, * \mathbb{C}}$, Joanna Majerska ${ }^{3}$, Jessica Brzezowska ${ }^{1}$, \\ Aneta Wojdyło ${ }^{1(1)}$ and Adam Figiel ${ }^{3}$ (i) \\ 1 Department of Fruit, Vegetable and Plant Nutraceutical Technology, the Faculty of Biotechnology and Food \\ Science, Wrocław University of Environmental and Life Sciences, ul. Chełmońskiego 37, 51-630 Wrocław, \\ Poland; jessica.brzezowska@upwr.edu.pl (J.B.); aneta.wojdylo@upwr.edu.pl (A.W.) \\ 2 Department of Chemistry and Biodynamics of Food, Institute of Animal Reproduction and Food Research of \\ the Polish Academy of Sciences, ul. Tuwima 10, 10-748 Olsztyn, Poland \\ 3 Institute of Agricultural Engineering, The Faculty of Life Sciences and Technology, Wrocław University of \\ Environmental and Life Sciences, ul. Chełmońskiego 37, 51-630 Wrocław, Poland; \\ joanna.majerska@upwr.edu.pl (J.M.); adam.figiel@upwr.edu.pl (A.F.) \\ * Correspondence: anna.michalska@upwr.edu.pl; Tel.: +48-71-3207712
}

Received: 6 September 2019; Accepted: 12 February 2020; Published: 17 February 2020

check for updates

\begin{abstract}
Cranberry juice has a high content of polyphenols, which makes it a valuable raw material with health-promoting properties. On the other hand, the bitter and astringent taste of cranberry limits its consumption in fresh form (fruit, juice). For this reason, new formulations of cranberry products based on natural additives are sought, e.g., in the form of carriers, which not only allow the drying of liquids to form powders, but which can also affect the retention of bioactive compounds. This study aimed at the evaluation of the influence of different carriers and concentrations applied to cranberry juice and their influence on the physico-chemical properties of the powders obtained. Freeze-dried powders had approximately eight times higher moisture content than products gained after the spray-drying process. The bulk density of freeze-dried product was approximately $11 \%$ higher when compared to spray-drying. Freeze-drying and spray-drying had a similar influence on the total polyphenolic compound content and antioxidant capacity. When the concentration of carriers was concerned, it was indicated that a higher content of carrier resulted in a lower moisture content, water activity, CIE $L^{*} a^{*} b^{*}$ coordinates, total polyphenolic content, and antioxidant capacity of the powders obtained, pointing to a strong influence of the juice composition on the final properties of the powders.
\end{abstract}

Keywords: Vaccinium macrocarpon L., carrier; freeze-drying; spray-drying; physico- chemical properties

\section{Introduction}

Cranberry (Vaccinium macrocarpon L.) is commonly cultivated in the United States, Canada, and Chile, as well as in some regions in northern Europe including areas of Germany, Holland, Belarus, and Poland [1]. This evergreen dwarf shrub has numerous proven health-related properties (e.g., prevention of urinary tract infections, reduction of the risk of cardiovascular diseases, detoxifying properties) due to the presence of the vitamins A, B, C, and E, dietary fiber, minerals, and polyphenolic compounds [2]. Cranberry is an excellent source of biologically active components, especially procyanidins, anthocyanins, phenolic acids, flavonols, and flavan-3-ols, which are generally responsible for its relatively high antioxidant potential [3-6]. The composition of polyphenols influences the bitter and astringent taste of cranberry fruits that makes them unattractive as a diet component, 
especially in a fresh form. That is why numerous attempts were made to convert cranberry into a food additive without the unacceptable taste for consumers and its negative influence on the final products. Cranberry can be found on the market as an ingredient of tea infusions, osmotically dehydrated in a sugar solution, as a dried product (prevention of its bitterness), and even as cranberry snacks [7]. The novel generation of cranberry products could be powders obtained from cranberry juice or extracts. Such products might be used as a food ingredients or nutraceuticals due to the unique composition of bioactive constituents [6,8]. The quality of such products is strictly dependent on the method of juice preparation $[9,10]$ the drying method applied, and the parameters used for their production. The possibility of powdering fruit juices is strictly connected to the presence of organic acids and low-molecular-weight compounds, which hinder the conversion of juice to powder due to the relatively low glass transition temperature, high hygroscopicity, etc. [11]. Such difficulties might be overcome by the addition of a carrier that enables the production of fruit juice powders.

One of the most common carriers used for powder production is maltodextrin. It was previously applied for the preparation of watermelon, mango, acai, and cranberry powders, among others [6,12-14]. From a technological point of view, maltodextrin is a better carrier agent when compared to, e.g., inulin, as maltodextrin has a lower potential to condense the solution before the spray-drying process $[6,14]$. Currently, maltodextrin is applied as a fat replacer, thereby lowering the caloric values in selected food stuffs [15]. Different types of maltodextrin are available, which can be divided according to the type of starch used for hydrolysis, e.g., potato, rice, corn, or oat; alternatively, barley and wheat are examples of less commonly used types of starch [16]. Differences between maltodextrins may also result from different values of glucose equivalent, as well as the way in which these additives affect human health [17-21]. Thus, carriers used for preserving or improving food properties may have different effects on human health; therefore, such components should be used with consideration of their influence on biological properties in vivo. The application of mixtures consisting of different carriers may provide an advantage from a technological point of view, as such a combination of carriers can be beneficial for drying, due to the formulation of particles, as well as the final physical properties of the powders obtained. Due to the increased awareness of consumers with regard to a healthy lifestyle, there is a need for the application of a carrier that could have additional benefits for human heath, in addition to facilitation of the drying process. One such product can be inulin, which is widely used in the food sector due to its technological and functional features [22]. Inulin is a natural polysaccharide present in various plants [23]. It has numerous health-related properties including stimulation of the immune system, regulation of food intake and appetite, intestinal acceptability, prebiotic function, etc. [24]. Apart from these, inulin can be used as a sweetener by replacing sucrose. It is comparatively less sweet, and it has a lower glycemic index $(G I=14)$ and lower caloric value $(1.5 \mathrm{kcal} / \mathrm{g})$; thus, it can be recommended for diabetics [25].

In addition to the influence of the carrier agent, the drying method and the parameters applied should be taken into account when the quality of fruit powders is concerned. Currently, freeze-, vacuum-, and-spray-drying are used to obtain cranberry juice powders [6,26]. It was demonstrated that spray-drying could improve the retention of polyphenolic compounds, with values similar to those gained after the freeze-drying process when compared to other drying methods. Taking the above factors into consideration, the aim of this study was to evaluate the influence of the addition of inulin and maltodextrin, as well as the effect of the drying method (freeze- and spray-drying), on the physical and chemical properties of the powders obtained from formulation containing cranberry juice.

\section{Materials and Methods}

\subsection{Reagents}

The 2,2-azino-bis(3-ethylbenzothiazoline-6-sulfonic acid) diammonium salt (ABTS), potassium persulfate, 2,4,6-tris(2-pyridyl)-s-triazine, and Trolox ${ }^{\circledR}$ were from Sigma-Aldrich (Buchs, Switzerland). 


\subsection{Material}

The material under study was the juice of cranberry cv. "Pilgrim" obtained using a hydraulic press (SRSE, Warsaw, Poland) (7.72\% dry matter-DM). The juice was mixed with different concentrations $(15 \%, 25 \%, 35 \% ; w / w)$ of inulin (Beneo-Orafti, Commercial inulin Orafti HSI; approximately $88 \%$ of inulin content-highly soluble inulin; Belgium), maltodextrin (Dextrose Equivalent (DE): 20-30), and a mixture of maltodextrin-inulin $(2: 1 ; w / w)$. Carrier concentrations were selected based on previous research by Michalska et al. [6] on cranberry products. The solutions were dehydrated using freezeand spray-drying.

\subsection{Methods}

\subsubsection{Drying Methods}

Freeze-drying (FD) of each prepared solution was carried out in a freeze-dryer (Alpha 1-4 LSC (Martin Christ $\mathrm{GmbH}$, Osterode am Harz, Germany) for $24 \mathrm{~h}$. The temperature within the drying chamber was $-60^{\circ} \mathrm{C}$, while the heating plates had a temperature of about $30^{\circ} \mathrm{C}$. Spray-drying (SD) was done in a mini spray-dryer (Mini spray-dryer, B-290, Büchi Labor Technik AG, Flawil, Switzerland). Droplets of the mixtures containing juice and the appropriate carrier were evaporated in hot air, with an inlet temperature of $180^{\circ} \mathrm{C}$ and outlet temperature of $70^{\circ} \mathrm{C}$. The drying processes were done in duplicate $(n=2)$.

\subsubsection{Physical Properties}

\section{Moisture Content}

The moisture content $(M C)$ of the powders obtained was measured by the vacuum-oven method (dry matter), using a vacuum oven (Vacucell 111 EcoLine MMM Group, Munchen, Germany) equipped with a vacuum pump (MZ 2C NT + AK + EK, Vacuum Brand GmbH, Wertheim, Germany) at a temperature of $80^{\circ} \mathrm{C}$ for $20 \mathrm{~h}$ according to Figiel [27]. The measurements were done in triplicate $(n=3)$.

\section{Water Activity}

Water activity $\left(a_{w}\right)$ was measured in triplicate $(n=3)$ using an AQUA LAB DewPoint water activity meter (Pullman, WA, USA) at a temperature of $25^{\circ} \mathrm{C} \pm 2{ }^{\circ} \mathrm{C}$.

\section{Bulk Density}

Bulk density was measured using a graduated cylinder $\left(10 \mathrm{~cm}^{3}\right)$ and laboratory scales PS $4500 \mathrm{R} 2$ (Radwag, Radom, Poland) and calculated according to the following equation (Equation (1)):

$$
\rho_{b}=\frac{m_{c}}{V_{c}}
$$

where $m_{c}$ is the sample mass in the cylinder, and $V_{c}$ is the sample volume in cylinder.

Bulk density was measured in triplicate $(n=3)$.

\section{Color}

The color of the powders obtained was determined by designating coordinates in the CIE $L^{*} a^{*} b^{*}$ color space using a Chroma Meter CR-400 (Minolta Co. Ltd., Osaka, Japan) and the standard illuminant D65 (average daylight). The apparent (surface) color of samples was measured in terms of $L^{*}$-lightness, $a^{*}$-red-green axis, and $b^{*}$-blue-yellow axis using a standard colorimetric observer with a $2^{\circ}$ field of view. The samples were placed on the measuring head of the Chroma Meter and the color attributes of the samples were measured. The measurements were performed in quintuplicate $(n=5)$. 


\subsubsection{Chemical Properties}

\section{Preparation of Extracts}

Cranberry powders were subjected to extraction with $80 \%$ aqueous methanol $(v / v)(50 \mathrm{mg}$ of each powder in $1.7 \mathrm{~mL}$ ) followed by sonication in a bath for $15 \mathrm{~min}$. Samples were left for $24 \mathrm{~h}$ in a $4{ }^{\circ} \mathrm{C}$ and were sonicated for $15 \mathrm{~min}$. After the centrifugation at $4800 \mathrm{rpm}$ (MPW-251, MPW Med. Instruments, Warszawa, Poland), the obtained extracts were prepared for the further analyses.

\section{Total Polyphenolic Compounds}

Total phenolic compounds (TPC) were determined according to Shahidi and Naczk [28]. Briefly, $100 \mu \mathrm{L}$ of extract was placed into a cuvette, followed by the addition of $0.2 \mathrm{~mL}$ of Folin-Ciocalteu phenol reagent and $2 \mathrm{~mL}$ of deionized water. The mixture was left for $3 \mathrm{~min}$ and then the $20 \% \mathrm{Na}_{2} \mathrm{CO}_{3}$ solution was added. The mixture was shaken before measuring the absorbance at $725 \mathrm{~nm}$. All determinations were performed in triplicate $(n=3)$ using a Shimadzu UV-2401 PC spectrophotometer (Kyoto, Japan). The results obtained were expressed as $\mathrm{mg}$ of gallic acid equivalent (GAE) per $100 \mathrm{mg}$ of dry matter (DM).

\section{Antioxidant Capacity}

The antioxidant capacity of cranberry powder extract was obtained following the sonication $(2 \times 15 \mathrm{~min})$ of $50 \mathrm{mg}$ of samples in $1.7 \mathrm{~mL}$ of $80 \%$ aqueous methanol $(v / v)$. After being kept for $24 \mathrm{~h}$ at $4{ }^{\circ} \mathrm{C}$ in the dark, the extracts were centrifuged. The extract (v) was evaluated in in vitro tests, i.e., using the ABTS radical cation decolorization assay (Trolox equivalent antioxidant capacity determined using ABTS assay; TEAC ABTS) [29]. Aliquots of $10 \mathrm{~mL}$ of the sample were placed into microplate wells followed by the addition of $290 \mu \mathrm{L}$ of ABTS.+ ${ }^{+}$solution (after incubation with $\mathrm{K}_{2} \mathrm{~S}_{2} \mathrm{O}_{8}$ ) using the microplate reader's injector. The reaction was carried out at $30^{\circ} \mathrm{C}$ in the dark for $6 \mathrm{~min}$. After this time, the values of absorbance were recorded at $734 \mathrm{~nm}$. Ferric reducing antioxidant potential (FRAP) was conducted according to Benzie and Strain [30]. Aliquots of $50 \mu \mathrm{L}$ of the sample were introduced to the well followed by the automatic addition of $300 \mu \mathrm{L}$ of freshly prepared FRAP reagent. The solution was left for $5 \mathrm{~min}$ at ambient temperature, and the absorbance was then measured at $593 \mathrm{~nm}$. The analysis was performed in duplicate $(n=2)$, and its results were presented as an average and expressed in mmol Trolox/100 g DM.

\section{Statistical Analysis}

One-way analysis of variance (ANOVA) and the least significance test Honest Significant Differences (HSD) Tukey $(p \leq 0.05)$ were applied to compare the samples. In order to investigate the relationship between selected variables, the Pearson correlation coefficient was calculated. Statistical analyses were performed using STATISTICA 13 (StatSoft, Tulsa, OK, USA).

\section{Results and Discussion}

\subsection{Physical Properties}

Table 1 indicates the physical properties of the carrier agents used, i.e., inulin (I), maltodextrin (M), and the mixture of maltodextrin and inulin (MI), as well as the cranberry powders gained after freeze- and spray-drying processes. Among the carrier agents, the highest moisture content was noted for M, followed by MI and I. The water activity of carriers ranged from 0.146 up to 0.294 and was the highest in the case of maltodextrin, in correlation with the moisture content $(r=0.994)$. The bulk density of the carriers differed due to the particle size [13]. 
Table 1. Physical properties of carriers and freeze- and spray-dried cranberry powders $(n=2)$, average \pm standard deviation).

\begin{tabular}{|c|c|c|c|c|c|}
\hline \multirow{2}{*}{$\begin{array}{l}\text { Drying } \\
\text { Method }\end{array}$} & \multirow[t]{2}{*}{ Carrier } & $\begin{array}{c}\text { Concentration } \\
\text { of Carrier }\end{array}$ & MC & $a_{w}$ & $\rho_{\mathrm{b}}$ \\
\hline & & $(\%)$ & $(\%)$ & $(-)$ & $\left(\mathrm{g} \cdot \mathrm{cm}^{-3}\right)$ \\
\hline \multirow{3}{*}{$(-)$} & \multirow{3}{*}{$\begin{array}{c}\text { Inulin } \\
\text { Maltodextrin } \\
\text { Maltodextrin-Inulin } \\
(2: 1)\end{array}$} & \multirow{3}{*}{$(-)$} & $3.44 \pm 0.01 b c$ & $0.15 \pm 0.005^{h}$ & $0.72 \pm 0.01 \mathrm{abc}$ \\
\hline & & & $6.43 \pm 0.03$ de & $0.29 \pm 0.002^{k}$ & $0.68 \pm 0.14^{a b c}$ \\
\hline & & & $5.90 \pm 0.00^{\mathrm{d}}$ & $0.25 \pm 0.002^{\mathrm{i}}$ & $0.89 \pm 0.04^{c}$ \\
\hline \multirow{9}{*}{ FD } & \multirow{3}{*}{ Inulin } & $15 \%$ & $4.34 \pm 0.02^{c}$ & $0.06 \pm 0.006 \mathrm{de}$ & $0.47 \pm 0.03^{a b}$ \\
\hline & & $25 \%$ & $3.07 \pm 0.02 b c$ & $0.03 \pm 0.001^{\mathrm{ab}}$ & $0.45 \pm 0.01^{a b}$ \\
\hline & & $35 \%$ & $2.50 \pm 0.02^{b}$ & $0.02 \pm 0.001^{\mathrm{a}}$ & $0.56 \pm 0.01 \mathrm{abc}$ \\
\hline & \multirow{3}{*}{ Maltodextrin } & $15 \%$ & $7.78 \pm 0.12^{f}$ & $0.30 \pm 0.001^{1}$ & $0.73 \pm 0.02 \mathrm{abc}$ \\
\hline & & $25 \%$ & $7.23 \pm 0.04 \mathrm{ef}^{\mathrm{ef}}$ & $0.40 \pm 0.001^{n}$ & $0.72 \pm 0.02^{a b c}$ \\
\hline & & $35 \%$ & $6.81 \pm 0.01$ def & $0.36 \pm 0.001^{1}$ & $0.71 \pm 0.00^{a b c}$ \\
\hline & \multirow{3}{*}{$\begin{array}{l}\text { Maltodextrin-Inulin } \\
\qquad(2: 1)\end{array}$} & $15 \%$ & $7.86 \pm 0.53^{f}$ & $0.29 \pm 0.001^{j k}$ & $0.65 \pm 0.01 \mathrm{abc}$ \\
\hline & & $25 \%$ & $6.87 \pm 1.29 \mathrm{def}$ & $0.28 \pm 0.001^{j}$ & $0.78 \pm 0.02^{b c}$ \\
\hline & & $35 \%$ & $6.28 \pm 0.01$ de & $0.39 \pm 0.003^{\mathrm{m}}$ & $0.76 \pm 0.00^{b c}$ \\
\hline \multirow{9}{*}{ SD } & \multirow{3}{*}{ Inulin } & $15 \%$ & $1.10 \pm 0.04^{\mathrm{a}}$ & $0.10 \pm 0.001 \mathrm{~g}$ & $0.48 \pm 0.00 \mathrm{ab}$ \\
\hline & & $25 \%$ & $0.75 \pm 0.01^{\mathrm{a}}$ & $0.06 \pm 0.001^{\mathrm{e}}$ & $0.60 \pm 0.00^{a b c}$ \\
\hline & & $35 \%$ & $1.01 \pm 0.10^{\mathrm{a}}$ & $0.06 \pm 0.001^{\mathrm{e}}$ & $0.67 \pm 0.02 \mathrm{abc}$ \\
\hline & \multirow{3}{*}{ Maltodextrin } & $15 \%$ & $0.95 \pm 0.04^{\mathrm{a}}$ & $0.08 \pm 0.002^{f}$ & $0.62 \pm 0.01 \mathrm{abc}$ \\
\hline & & $25 \%$ & $0.58 \pm 0.10^{\mathrm{a}}$ & $0.05 \pm 0.001^{\mathrm{cd}}$ & $0.62 \pm 0.02^{a b c}$ \\
\hline & & $35 \%$ & $0.73 \pm 0.07^{\mathrm{a}}$ & $0.04 \pm 0.000^{b}$ & $0.50 \pm 0.02 \mathrm{abc}$ \\
\hline & \multirow{3}{*}{$\begin{array}{c}\text { Maltodextrin-Inulin } \\
(2: 1)\end{array}$} & $15 \%$ & $0.85 \pm 0.05^{\mathrm{a}}$ & $0.08 \pm 0.003^{f}$ & $0.61 \pm 0.01^{a b c}$ \\
\hline & & $25 \%$ & $0.62 \pm 0.011^{a}$ & $0.05 \pm 0.002^{\mathrm{cd}}$ & $0.61 \pm 0.03^{a b}$ \\
\hline & & $35 \%$ & $0.32 \pm 0.01^{\mathrm{a}}$ & $0.05 \pm 0.002^{c}$ & $0.39 \pm 0.01^{\mathrm{a}}$ \\
\hline
\end{tabular}

FD—freeze-drying, SD—spray-drying, MC—-moisture content, $a_{w}$-water activity, $\rho_{b}$-bulk density; ${ }^{a, b, c, d}$ the same letters within a column indicate no statistically significant differences (HSD Tukey test, $p \leq 0.05$ ).

The moisture content of freeze-dried powders ranged from $2.5 \%$ up to $7.8 \%$ for products gained from the juice formulation containing 35\% I and 15\% MI. It was noted that a lower carrier addition resulted in a higher moisture content of the powders obtained. After the freeze-drying process, the powders prepared with inulin had the lowest MC when compared to powders obtained after the addition of maltodextrin and the mixture of maltodextrin and inulin. This might be connected to the initial moisture content of inulin (Table 1). The moisture content of cranberry spray-dried powders ranged from $0.319 \%$ up to $1.095 \%$ for powders obtained from the juice formulation containing $35 \%$ MI and 15\% I, respectively. In general, the spray-drying process resulted in a lower moisture content (approximately $87 \%$ ) in comparison to powders gained after the freeze-drying process, regardless of the type of carrier and the concentration used for the preparation of feed solutions. A similar observation was made in case of apple powders [31]. Likewise, in the studies on the watermelon, Gac, and ginger juice [14,32-34], it was observed that a higher content of carrier in the feed solution resulted in a lower moisture content of the powders obtained, pointing to a strong influence of the carrier concertation on the powders' final properties. This resulted from higher total solid contents in the feed solution and, thus, less water for evaporation during the drying process. Where the type of carrier agent was concerned, it was noted that the addition of inulin into the cranberry juice resulted in a higher moisture content of spray-dried powders when compared to products containing maltodextrin. Taking into account a relatively high temperature during spray-drying and the significantly shorter time of water removal, handling of powders might have more influence on the moisture content than the MC of the carrier added before drying. Furthermore, different interactions between the juice components and the carrier might occur when compared to the freeze-drying process. The carriers might have different water-holding capacity, which could also be moderated by the drying method [35]. A higher MC in powders obtained from the juice formulation containing inulin was probably connected to the chemical 
structure of the inulin, in which fructose units might have relatively higher hydrogen bonding when compared to maltodextrin components. Taking the above into consideration, inulin could be more susceptible to moisture [36], while it could be more easily bound by water molecules from the air during handling of the spray-dried powders [37].

Similarly to watermelon and apple juice powders, the average $a_{w}$ of the cranberry powders obtained after the freeze-drying process was approximately 3.9 times higher when compared to powders obtained after the spray-drying process, regardless of the type of carrier used and the concentration applied for feed preparation [14,31]. In general, among the powders gained after the freeze-drying process, the increased concentration of carriers lowered the water activity of the products, which was also observed in case of Cagaita powders [38]. The type of carrier had an impact on the $a_{w}$ values of the cranberry powders, as the addition of maltodextrin resulted in the highest water activity when compared to the maltodextrin-inulin mixture and inulin. This might be influenced by the $a_{w}$ of carriers (Table 1). Interestingly, the water activity of powders obtained with inulin was significantly lower, regardless of the carrier concentration. A similar observation was noted in the study on blackcurrant powders gained from the juice formulation containing inulin and other carrier agents, i.e., maltodextrins with different DE, starch, and Arabic gum in which the freeze-dried powders with inulin had drastically lower water activity (unpublished data). It can be noticed that interactions between the inulin and fruit juices that occur during freezing might have an impact on the final properties of powders obtained. In the case of spray-drying, the water activity of powders differed due to the carrier type and concentration added to the juice before powdering. Furthermore, a strong correlation between the MC and $a_{w}$ of freeze-dried powders was observed $(r=0.909)$. Contrary to freeze-drying, the highest $a_{w}$ was indicated when inulin was added into the juice formulation before spray-drying (on average, $a_{w}=0.075$ ) when compared to powders gained with maltodextrin (on average, $a_{w}=0.055$ ). The results obtained were approximately four times lower when compared to cherry powders with the addition of a similar concentration of maltodextrin [39]. This pointed to a strong influence of the juice composition of the quality of the final products. It was observed that a higher content of carrier in the feed solution led to a lower water activity of the spray-dried powders. Taking the above into consideration, the quality of the cranberry powders might be modified by the type of carrier and the drying method used for its preparation.

In the case of food powders, one of the most important physical parameters is the bulk density, which determines the economic influence of the products for shipment, packing, and transport costs [40]. It was noted that the bulk density of the carriers, i.e., inulin, maltodextrin, and the mixture of maltodextrin and inulin, was not statistically different (Table 1); however, the lowest value was noted in the case of maltodextrin and the highest was indicated for the mixture of maltodextrin and inulin. In the case of cranberry powders gained after the freeze-drying process, the bulk density was more affected by the type of carrier than its concentration. An average value of bulk density of powders gained from the juice formulation containing inulin was approximately $30 \%$ lower when compared to that obtained from juices with the mixture of both carriers. The results were in agreement with the observations made by Bhusari et al. [41]. A high correlation between the bulk density and moisture content $(r=0.808)$ and water activity $(r=0.911)$ was noted. The bulk density values after the spray-drying process ranged from 0.390 up to $0.665 \mathrm{~g} \cdot \mathrm{cm}^{-3}$ and were in agreement with the bulk density of powders gained using juice from raisins with maltodextrin addition [42]. In general, the freeze-dried powders had higher bulk density by approximately $11 \%$ when compared to the spray-dried products. In the case of maltodextrin and the mixture of maltodextrin and inulin, similarly to Bhusari et al. [41], Goula and Adamopoulos [43], and Moghaddam et al. [44], the bulk density of cranberry powders decreased within the increase in the concentration of the carrier. Tontul and Topuz [35] suggested that such behavior of the powders might be connected to the prevention of sticking by selected carriers. On the other hand, when the inulin was added, the increase in concentration of this carrier resulted in an increase in bulk density of the cranberry powders. 
The differences between the values of coordinates $L^{*}, a^{*}$, and $b^{*}$ of the cranberry powders obtained after freeze- and spray-drying are indicated in Table 2. Similarly to Michalska et al. [6], darker products were gained after freeze-drying than after the spray-drying process. It was noted that a higher concentration of the carrier resulted in lighter products obtained (higher $L^{*}$ values), regardless of the drying method used for powder preparation. In the case of powders from Gac fruit (Momordica cochinchinensis L.) juice containing maltodextrin, lighter products were also obtained along with the increasing concentration of the carrier [33]. Among the freeze-dried powders, darker products were obtained after addition of inulin when compared to powders containing $\mathrm{M}$ and MI. The powders containing inulin obtained after freeze-drying showed higher values of coordinate $L^{*}$ than after spray-drying, which may be related to the water activity of powders. In the powders obtained after freeze-drying, lower water activity and lighter color were noticed, whereas, after spray-drying, higher water activity and a darker color of powders were indicated. In the studies performed by Michalska and Lech [31], powders of the apple juice containing maltodextrin were lighter after the freeze-drying process when compared to spray-drying. When the coordinate $a^{*}$ was concerned, the increase in the concentration of the carrier caused a decrease in the $a^{*}$ values. Among carriers applied, maltodextrin seems to most preserve the red color of the powders, regardless of the concentration used in the feed preparation. A similar observation was made for the coordinate $b^{*}$. Where the spray-drying process was concerned, the opposite effect of the carrier on the lightness of the powders was indicated. In this case, the lightest products were obtained using juice formulation containing mixture of maltodextrin and inulin, whereas the addition of inulin resulted in the darkest powders. At the same time, inulin protected the red pigments (coordinate $a^{*}$ ) and $b^{*}$ values to the highest extent, even when compared to freeze-dried powders. Thus, the type of carrier and the drying method applied had a strong influence on the coordinated $L^{*}, a^{*}$, and $b^{*}$ values [31].

Table 2. The color parameters (CIE $\left.L^{*} a^{*} b^{*}\right)$ of cranberry powders obtained after freeze- and spray-drying ( $n=5$, average \pm standard deviation).

\begin{tabular}{|c|c|c|c|c|c|}
\hline \multirow{2}{*}{$\begin{array}{l}\text { Drying } \\
\text { Method }\end{array}$} & \multirow[t]{2}{*}{ Carrier } & \multirow{2}{*}{$\begin{array}{c}\begin{array}{c}\text { Concentration } \\
\text { of Carrier }\end{array} \\
(\%)\end{array}$} & \multicolumn{3}{|c|}{ Color } \\
\hline & & & $L^{*}$ & $a^{*}$ & $b^{*}$ \\
\hline \multirow{9}{*}{ FD } & \multirow{3}{*}{ Inulin } & $15 \%$ & $62.33 \pm 0.18^{g}$ & $35.92 \pm 0.47^{\mathrm{cd}}$ & $5.89 \pm 0.17^{c}$ \\
\hline & & $25 \%$ & $67.24 \pm 0.05^{j}$ & $32.68 \pm 0.14^{b}$ & $4.13 \pm 0.02^{b}$ \\
\hline & & $35 \%$ & $70.22 \pm 0.20^{1}$ & $29.08 \pm 0.49^{a}$ & $3.42 \pm 0.07^{a}$ \\
\hline & \multirow{3}{*}{ Maltodextrin } & $15 \%$ & $51.05 \pm 0.40^{\mathrm{a}}$ & $43.37 \pm 0.42^{\mathrm{kl}}$ & $11.13 \pm 0.40^{j}$ \\
\hline & & $25 \%$ & $57.88 \pm 0.55^{c}$ & $39.07 \pm 0.31 \mathrm{hi}$ & $8.54 \pm 0.20 \mathrm{~g}$ \\
\hline & & $35 \%$ & $60.26 \pm 0.55^{\mathrm{ef}}$ & $37.67 \pm 0.94 \mathrm{fg}$ & $7.41 \pm 0.39 \mathrm{e}$ \\
\hline & \multirow{3}{*}{$\begin{array}{l}\text { Maltodextrin-Inulin } \\
(2: 1)\end{array}$} & $15 \%$ & $54.57 \pm 0.42^{b}$ & $40.31 \pm 0.58^{j}$ & $9.33 \pm 0.27^{\mathrm{h}}$ \\
\hline & & $25 \%$ & $59.19 \pm 0.30^{d}$ & $38.17 \pm 0.50 \mathrm{gh}$ & $8.22 \pm 0.24^{\mathrm{fg}}$ \\
\hline & & $35 \%$ & $61.64 \pm 0.10^{g}$ & $36.41 \pm 0.07 \mathrm{de}$ & $7.28 \pm 0.04^{\mathrm{e}}$ \\
\hline \multirow{9}{*}{ SD } & \multirow{3}{*}{ Inulin } & $15 \%$ & $59.99 \pm 0.12$ ef & $44.29 \pm 0.27^{1}$ & $11.5 \pm 0.11^{j}$ \\
\hline & & $25 \%$ & $64.16 \pm 0.27^{h}$ & $40.85 \pm 0.21^{\mathrm{k}}$ & $9.64 \pm 0.06^{h}$ \\
\hline & & $35 \%$ & $65.19 \pm 0.34^{\mathrm{i}}$ & $39.64 \pm 0.57^{\mathrm{jk}}$ & $9.30 \pm 0.11^{h}$ \\
\hline & \multirow{3}{*}{ Maltodextrin } & $15 \%$ & $60.68 \pm 0.24^{f}$ & $42.28 \pm 0.08^{k}$ & $10.28 \pm 0.10^{\mathrm{i}}$ \\
\hline & & $25 \%$ & $65.28 \pm 0.47^{\mathrm{i}}$ & $39.33 \pm 0.18^{h i}$ & $8.14 \pm 0.09 \mathrm{fg}$ \\
\hline & & $35 \%$ & $68.15 \pm 0.18^{k}$ & $37.45 \pm 0.11$ efg & $6.70 \pm 0.02^{d}$ \\
\hline & \multirow{3}{*}{$\begin{array}{l}\text { Maltodextrin-Inulin } \\
\qquad(2: 1)\end{array}$} & $15 \%$ & $59.91 \pm 0.32 \mathrm{de}$ & $42.59 \pm 0.40^{\mathrm{k}}$ & $10.57 \pm 0.15^{\mathrm{i}}$ \\
\hline & & $25 \%$ & $66.60 \pm 0.30^{j}$ & $36.70 \pm 1.58$ def & $7.95 \pm 0.41^{\mathrm{f}}$ \\
\hline & & $35 \%$ & $70.40 \pm 0.07^{1}$ & $34.81 \pm 0.40^{c}$ & $6.55 \pm 0.10^{d}$ \\
\hline
\end{tabular}

FD—freeze-drying, SD—spray-drying; ${ }^{a}, b, c, d$ the same letters within a column indicate no statistically significant differences (HSD Tukey test, $p \leq 0.05$ ).

\subsection{Chemical Properties}

The content of total polyphenolic compounds (TPC) determined by the spectrophotometric method in cranberry cv. Pilgrim was $120 \mathrm{mg} / 100 \mathrm{~g}$ [39]. In the present study, the TPC content ranged 
from 127.7 up to $354.1 \mathrm{mg}$ GAE/100 g DM for powders obtained using 35\% maltodextrin and 15\% maltodextrin after freeze-drying. In general, the highest content of compounds able to react with the Folin reagent was indicated for products with the lowest addition of carrier $(15 \%)$, regardless of the type of carrier used for drying. The average TPC content in powders obtained from the formulation of cranberry juice with $25 \%$ and $35 \%$ carrier was, respectively, $36 \%$ and $54 \%$ lower when compared to that gained with a $15 \%$ addition of carrier agent. A similar observation was made in the case of amla and Cagaita juice powders pointing to a concentration effect of the carrier on the properties of the final products [45,46]. Previously, Daza et al. [39] and Tonon et al. [47] indicated a strong influence of the type of carrier on the retention of total polyphenolic compounds in acai and Cagaita juice powders. In the current study, powders obtained from the formulation containing maltodextrin had better retention of TPC after freeze-drying when compared to powders with inulin and maltodextrin-inulin. In the case of spray-drying, powders with the juice formulation containing inulin had better retention of TPC only in the case of $15 \%$ and $25 \%$ addition. A comparison between the drying method applied indicated similar levels of TPC between the freeze-dried and spray-dried cranberry powders, regardless of the addition of the carrier agent. Taking into account the costs of the freeze-drying that were estimated to be six times more expensive than the removal of water by spray-drying [48,49], the latter process can be successfully applied for the cranberry powdering process. Furthermore, the retention of bioactive compounds was on a comparable level between these two drying techniques.

In the current study, the formulation of the cranberry juice and carriers with different concentration affected the antioxidant capacity of the powders obtained as measured by the TEAC ABTS and FRAP assay (Table 3). Similarly to plum juice powders [50], Cagaita (Eugenia dysenterica DC) juice powders and winter savory (Satureja montana) spray-dried powders [46,51], a higher concentration of the carrier in the feed solution, regardless of the type of carrier used, resulted in a lower antioxidant capacity of the powders obtained.

Table 3. The content of total polyphenolic compounds (TPC) and antioxidant capacity (Trolox equivalent antioxidant capacity (TEAC) ABTS, ferric reducing antioxidant potential (FRAP)) in cranberry powders gained by freeze- and spray-drying $(n=2$, average \pm standard deviation).

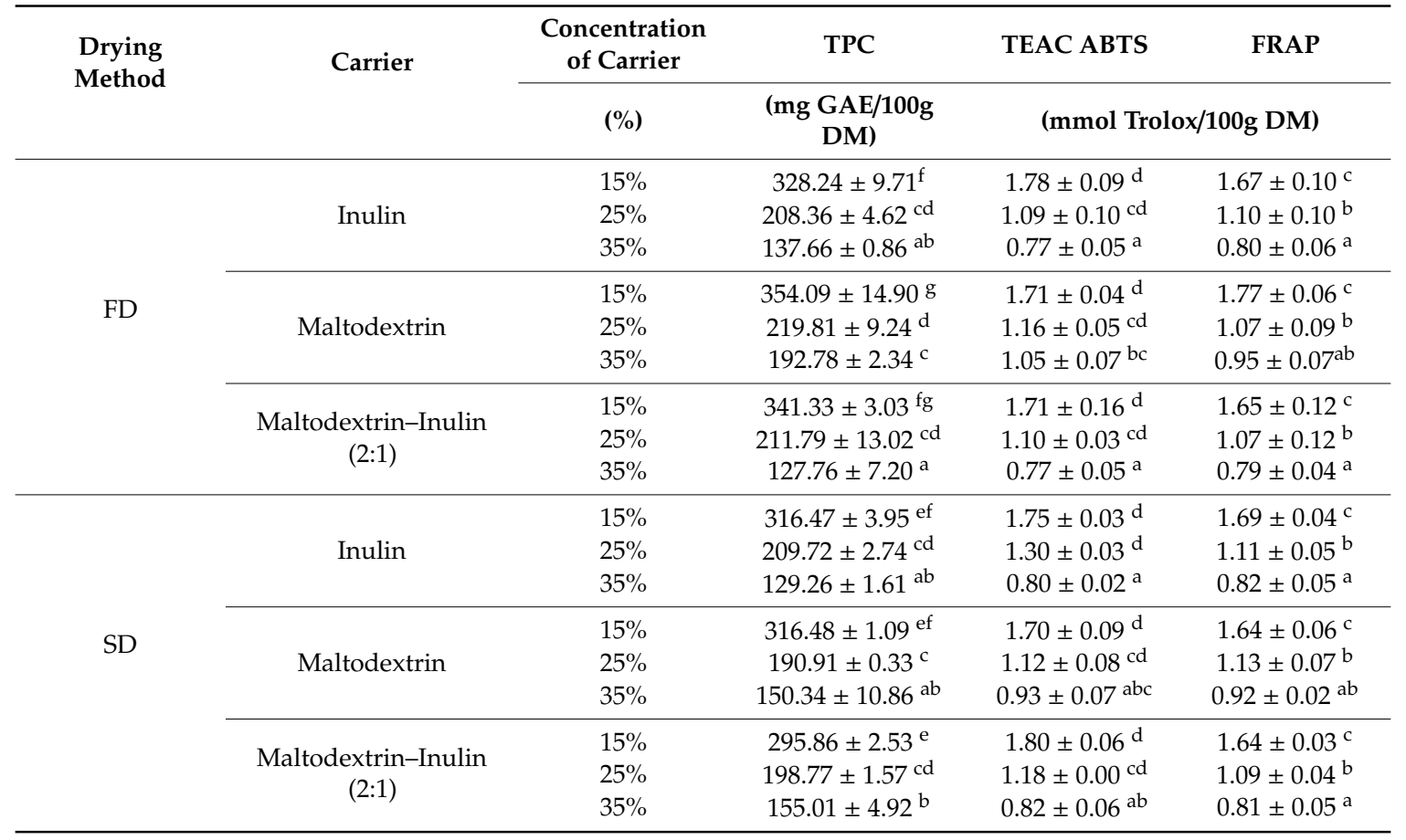

FD—freeze-drying, SD—spray-drying, TPC—total polyphenolic compounds, TEAC ABTS—Trolox equivalent antioxidant capacity measured against ABTS radical cations, FRAP-ferric reducing antioxidant potential, GAE-gallic acid equivalent; ${ }^{a, b}, c, d$ the same letters within a column indicate no statistically significant differences (HSD Tukey test, $p \leq 0.05$ ). 
In the current study, powders obtained from the formulation containing maltodextrin had a similar retention of compounds able to scavenge ABTS radical cations to powders gained with inulin and maltodextrin-inulin. In the case of spray-drying, powders with the juice formulation containing inulin had a slightly better retention of TPC only in the case of $15 \%$ and $25 \%$ carrier addition. It can be concluded that, in terms of the retention of bioactive components, both carriers had a similar effect. A significant positive correlation between total polyphenolic compounds and antioxidant capacity measured by TEAC ABTS $(r=0.971)$ and FRAP $(r=0.983)$ was noted. Results were in accordance with data reported by Daza et al. [46]. It can be concluded that the concentration of carrier in the feed solution had a stronger impact on the antioxidant capacity than the application of selected carrier agents.

\section{Conclusions}

Cranberry juice powders were obtained using different formulations containing inulin, maltodextrin, and a mixture of maltodextrin and inulin $(2: 1 ; w / w)$ in order to evaluate the physico-chemical properties of the powders gained after freeze- and spray-drying processes. The results indicated that the moisture content of powders was strongly dependent on the drying method applied. Freeze-dried powders had approximately eight times higher moisture content than products gained after the spray-drying process. The values of water activity were also approximately 3.9 times higher in powders gained after freeze-drying. Interestingly, the type of carrier had a significant impact on the water activity values after the freeze-drying process as powders obtained from the juice formulation containing inulin had the lowest values. The freeze-dried powders had approximately $11 \%$ higher bulk density when compared to spray-dried products. Where the concentration of carriers was concerned, it was indicated that a higher content of carrier led to a lower moisture content, water activity, $L^{*}, a^{*}$, and $b^{*}$ coordinates, total polyphenolic content, and antioxidant capacity of the powders obtained, pointing to a strong influence of the juice composition on the final properties of the powders.

Author Contributions: Conceptualization, A.M.-C.; data curation, J.M. and J.B.; formal analysis, A.M.-C. and A.W.; funding acquisition, A.M.-C.; investigation, A.M.-C., A.W., J.B., and J.M.; methodology, J.M. and J.B.; project administration, A.M.-C.; resources, A.M.-C., A.W., and A.F.; supervision, A.M.-C.; validation, J.M. and J.B.; visualization, A.M.-C.; writing-original draft preparation, A.M.-C.; writing-review and editing, A.M.-C., A.W., J.M., and A.F. All authors have read and agreed to the published version of the manuscript.

Funding: The study was supported by the National Science Center (Poland) [2016/23/D/NZ9/02671].

Acknowledgments: This publication is the result of the research group activity "Plants4food".

Conflicts of Interest: The authors declare no conflicts of interest. The funders had no role in the design of the study: in the collection, analyses, or interpretation of data; in the writing of the manuscript, or in the decision to publish the results.

\section{References}

1. Hummer, K.E.; Lewers, K.S.; Bassil, N.V.; Vorsa, N.; Zalapa, J.E.; Iorizzo, M.; Tzanetakis, I. Cranberry Vulnerability Statement; GRIN: Munich, Germany, 2018.

2. Borges, G.; Degeneve, A.; Mullen, W.; Crozier, A. Identification of flavonoid and phenolic antioxidants in black currants, blueberries, raspberries, red currants, and cranberries. J. Agric. Food Chem. 2009, 58, 3901-3909. [CrossRef]

3. Sun, J.; Chu, Y.F.; Wu, X.; Liu, R.H. Antioxidant and antiproliferative activities of common fruits. J. Agric. Food Chem. 2002, 50, 7449-7454. [CrossRef]

4. Blumberg, J.B.; Camesano, T.A.; Cassidy, A.; Kris-Etherton, P.; Howell, A.; Manach, C.; Vita, J.A. Cranberries and their bioactive constituents in human health. Adv. Nutr. Res. 2013, 4, 618-632. [CrossRef]

5. Oszmiański, J.; Wojdyło, A.; Lachowicz, S.; Gorzelany, J.; Matłok, N. Comparison of bioactive potential of cranberry fruit and fruit-based products versus leaves. J. Funct. Foods 2016, 22, 232-242. [CrossRef]

6. Michalska, A.; Wojdyło, A.; Honke, J.; Ciska, E.; Andlauer, W. Drying-induced physico-chemical changes in cranberry products. Food Chem. 2018, 240, 448-455. [CrossRef] 
7. Nowacka, M.; Wiktor, A.; Anuszewska, A.; Dadan, M.; Rybak, K.; Witrowa-Rajchert, D. The application of unconventional technologies as pulsed electric field, ultrasound and microwave-vacuum drying in the production of dried cranberry snacks. Ultrason. Sonochem. 2019, 56, 1-13. [CrossRef] [PubMed]

8. Oszmiański, J.; Kolniak-Ostek, J.; Lachowicz, S.; Gorzelany, J.; Matłok, N. Effect of dried powder preparation process on polyphenolic content and antioxidant capacity of cranberry (Vaccinium macrocarpon L.). Ind. Crops Prod. 2015, 77, 658-665. [CrossRef]

9. Côté, J.; Caillet, S.; Doyon, G.J.; Dussault, D.; Sylvain, J.F.; Lacroix, M. Antimicrobial effect of cranberry juice and extracts. Food Control. 2011, 22, 1413-1418. [CrossRef]

10. White, B.L.; Howard, L.R.; Prior, R.L. Impact of different stages of juice processing on the anthocyanin, flavonol, and procyanidin contents of cranberries. J. Agric. Food Chem. 2011, 59, 4692-4698. [CrossRef]

11. Bhandari, B.R.; Senoussi, A.; Lebert, A. Spray drying of concentrated fruit juices. Dry. Technol. 1993, 11, 1081-1092. [CrossRef]

12. Tonon, R.V.; Brabet, C.; Hubinger, M.D. Influence of process conditions on the physicochemical properties of açai (Euterpe oleraceae Mart.) powder produced by spray drying. J. Food Eng. 2008, 88, 411-418. [CrossRef]

13. Caparino, O.A.; Tang, J.; Nindo, C.I.; Sablani, S.S.; Powers, J.R.; Fellman, J.K. Effect of drying methods on the physical properties and microstructures of mango (Philippine 'Carabao' var.) powder. J. Food Eng. 2012, 111, 135-148. [CrossRef]

14. Oberoi, D.P.S.; Sogi, D.S. Effect of drying methods and maltodextrin concentration on pigment content of watermelon juice powder. J. Food Eng. 2015, 165, 172-178. [CrossRef]

15. Kasprzyk, I.; Markowska, J.; Polak, E. Zamienniki tłuszczu w produktach spożywczych. Przem. Spoż. 2016, 70, 19-22. (In Polish)

16. Fortuna, T.; Sobolewska, J. Maltodekstryny i ich wykorzystanie w przemyśle spożywczym. Żywn. Nauka Technol. Jakość 2000, 2, 100-109. (In Polish)

17. Hashizume, C.; Kishimoto, Y.; Kanahori, S.; Yamamoto, T.; Okuma, K.; Yamamoto, K. Improvement effect of resistant maltodextrin in humans with metabolic syndrome by continuous administration. J. Nutr. Sci. Vitaminol. 2012, 58, 423-430. [CrossRef]

18. Astina, J.; Sapwarobol, S. Resistant maltodextrin and metabolic syndrome: A review. J. Am. Coll. Nutr. 2019, 38, 380-385. [CrossRef]

19. Ross, R.; Janssen, I.; Dawson, J.; Kungl, A.M.; Kuk, J.L.; Wong, S.L.; Nguyen-Duy, T.B.; Lee, S.; Kilpatrick, K.; Hudson, R. Exercise-induced reduction in obesity and insulin resistance in women: A randomized controlled trial. Obes. Res. 2004, 12, 789-798. [CrossRef]

20. Nickerson, K.P.; McDonald, C. Crohn's disease-associated adherent-invasive Escherichia Coli adhesion is enhanced by exposure to the ubiquitous dietary polysaccharide maltodextrin. PLOS ONE 2012, 7, e52132. [CrossRef]

21. Nickerson, K.P.; Chanin, R.; McDonald, C. Deregulation of intestinal anti-microbial defense by the dietary additive, maltodextrin. Gut Microbes 2014, 6, 78-83. [CrossRef]

22. Shoaib, M.; Shehzad, A.; Omar, M.; Rakha, A.; Raza, H.; Sharif, H.R.; Niazi, S. Inulin: Properties, health benefits and food applications. Carbohydr. Polym. 2016, 147, 444-454. [CrossRef] [PubMed]

23. Marteau, P.; Seksik, P.; Lepage, P.; Doré, J. Cellular and physiological effects of probiotics and prebiotics. Mini Rev. Med. Chem. 2004, 4, 889-896. [CrossRef] [PubMed]

24. Vogt, L.; Meyer, D.; Pullens, G.; Faas, M.; Smelt, M.; Venema, K.; De Vos, P. Immunological properties of inulin-type fructans. Crit. Rev. Food Sci. 2015, 55, 414-436. [CrossRef] [PubMed]

25. Śliżewska, K.; Nowak, A.; Barczyński, R.; Libudzisz, Z. Prebiotyki-definicja, właściwości i zastosowanie w przemyśle. Żywn. Nauka Technol. Jakość 2013, 20, 5-20. (In Polish)

26. Martín, M.A.; Ramos, S.; Mateos, R.; Marais, J.P.J.; Bravo-Clemente, L.; Khoo, C.; Goya, L. Chemical characterization and chemo-protective activity of cranberry phenolic powders in a model cell culture. Response of the antioxidant defenses and regulation of signaling pathways. Food Res. Int. 2015, 71, 68-82. [CrossRef]

27. Figiel, A. Drying kinetics and quality of beetroots dehydrated by combination of convective and vacuum-microwave methods. J. Food Eng. 2010, 98, 461-470. [CrossRef] 
28. Shahidi, F.; Naczk, M. Methods of analysis and quantification of phenolic compounds. In Food Phenolic: Sources, Chemistry, Effects and Applications; Shahidi, F., Naczk, M., Eds.; Technomic Publishing Company: Lancaster, PA, USA, 1995; pp. 287-293.

29. Re, R.; Pellegrini, N.; Proteggente, A.; Pannala, A.; Yang, M.; Rice-Evans, C. Antioxidant activity applying an improved ABTS radical cation decolorization assay. Free Radic. Biol. Med. 1999, 26, 1231-1237. [CrossRef]

30. Benzie, I.F.F.; Strain, J.J. Ferric reducing/antioxidant power assay: Direct measure of total antioxidant activity of biological fluids and modified version for simultaneous measurement of total antioxidant power and ascorbic acid concentration. In Oxidants and Antioxidants Part A. Methods Enzymol. 1999, 299, 15-27.

31. Michalska, A.; Lech, K. The effect of carrier quantity and drying method on the physical properties of apple juice powders. Beverages 2018, 4, 2. [CrossRef]

32. Quek, S.Y.; Chok, N.K.; Swedlund, P. The physicochemical properties of spray-dried watermelon powders. Chem. Eng. Process. 2007, 46, 386-392. [CrossRef]

33. Kha, T.C.; Nguyen, M.H.; Roach, P.D. Effects of spray drying conditions on the physicochemical and antioxidant properties of the Gac (Momordica cochinchinensis) fruit aril powder. J. Food Eng. 2010, 98, 385-392. [CrossRef]

34. Phoungchandang, S.; Sertwasana, A. Spray-drying of ginger juice and physicochemical properties of ginger powders. Sci. Asia 2010, 36, 40-45. [CrossRef]

35. Tontul, I.; Topuz, A. Spray-drying of fruit and vegetable juices: Effect of drying conditions on the product yield and physical properties. Trends Food Sci. Technol. 2017, 63, 91-102. [CrossRef]

36. Souza, B.W.S.; Cerqueira, M.A.; Teixeira, J.A.; Vicente, A.A. The use of electric fields for edible coatings and films development and production: A review. Food Eng. Rev. 2010, 2, 244-255. [CrossRef]

37. Phisut, N. Spray drying technique of fruit juice powder: Some factors influencing the properties of product. Int. Food Res. J. 2012, 19, 1297-1306.

38. Daza, L.D.; Fujita, A.; Fávaro-Trindade, C.S.; Rodrigues-Ract, J.N.; Granato, D.; Genovese, M.I. Effect of spray drying conditions on the physical properties of Cagaita (Eugenia dysenterica DC.) fruit extracts. Food Bioprod. Process. 2016, 97, 20-29. [CrossRef]

39. Can Karaca, A.; Guzel, O.; Ak, M.M. Effects of processing conditions and formulation on spray drying of sour cherry juice concentrate. J. Sci. Food Agric. 2016, 96, 449-455. [CrossRef]

40. Schuck, P. Dairy powders. In Handbook of Food Powders; Smithers, G.W., Augustin, M.A., Eds.; John Wiley Sons, Inc.: New York, NY, USA; The Institute of Food Technologists: Chicago, IL, USA, 2013; pp. 437-464.

41. Bhusari, S.N.; Muzaffar, K.; Kumar, P. Effect of carrier agents on physical and microstructural properties of spray dried tamarind pulp powder. Powder Technol. 2014, 266, 354-364. [CrossRef]

42. Papadakis, S.; Gardeli, C.; Tzia, C. Spray drying of raisin juice concentrate. Dry. Technol. 2006, 24, $173-180$. [CrossRef]

43. Goula, A.M.; Adamopoulos, K.G. Effect of Maltodextrin Addition during Spray Drying of Tomato Pulp in Dehumidified Air: II. Powder Properties. Dry. Technol. 2008, 26, 726-737. [CrossRef]

44. Moghaddam, A.D.; Pero, M.; Askari, G.R. Optimizing spray drying conditions of sour cherry juice based on physicochemical properties, using response surface methodology (RSM). J. Food Sci. Technol. 2017, 54, 174-184. [CrossRef] [PubMed]

45. Mishra, P.; Mishra, S.; Mahanta, C.L. Effect of maltodextrin concentration and inlet temperature during spray drying on physicochemical and antioxidant properties of amla (Emblica officinalis) juice powder. Food Bioprod. Process. 2014, 92, 252-258. [CrossRef]

46. Daza, L.D.; Fujita, A.; Granato, D.; Silvia Fávaro-Trindade, C.; Inés Genovese, M. Functional properties of encapsulated Cagaita (Eugenia dysenterica DC.) fruit extract. Food Biosci. 2017, 18, 15-21. [CrossRef]

47. Tonon, R.V.; Brabet, C.; Pallet, D.; Brat, P.; Hubinger, M.D. Physicochemical and morphological characterisation of açai (Euterpe oleraceae Mart.) powder produced with different carrier agents. Int. J. Food Sci. Technol. 2009, 44, 1950-1958. [CrossRef]

48. Knorr, D. Technology aspects related to microorganisms in functional foods. Trends Food Sci. Technol. 1998, 9 , 295-306. [CrossRef]

49. Gouin, S. Microencapsulation: Industrial appraisal of existing technologies and trends. Trends Food Sci. Technol. 2004, 15, 330-347. [CrossRef]

50. Michalska, A.; Wojdyło, A.; Łysiak, G.P.; Figiel, A. Chemical composition and antioxidant properties of powders obtained from different plum juice formulations. Int. J. Mol. Sci. 2017, 18, 176. [CrossRef] 
51. Vidović, S.S.; Vladić, J.Z.; Vaštag, Ž.G.; Zeković, Z.P.; Popović, L.M. Maltodextrin as a carrier of health benefit compounds in Satureja montana dry powder extract obtained by spray drying technique. Powder Technol. 2014, 258, 209-215. [CrossRef] 